Accepted for publication in Polymers for Advanced Technologies Published in 2019

DOI: 10.1002/pat.4488 


\title{
Mechanical and thermal characterization of sisal fiber reinforced polylactic acid composites
}

\author{
Zineb SAMOUH ${ }^{1,2 *}$, Kolos MOLNAR ${ }^{3,4}$, François Boussu ${ }^{5}$, Omar CHERKAOUI $^{2}$, Reddad EL MOZNINE $^{1}$ \\ ${ }^{1}$ Laboratory LPMC, Faculty of Science El Jadida, Chouaib Doukkali University, El Jadida, Morocco \\ ${ }^{2}$ Laboratory REMTEX, ESITH (Higher School of Textile and Clothing Industries), Casablanca, Morocco \\ ${ }^{3}$ Department of Polymer Engineering, Faculty of Mechanical Engineering, Budapest University of Technology and \\ Economics, Budapest, Hungary \\ ${ }^{4}$ MTA-BME Research Group for Composite Science and Technology, Müegyetem rkp. 3., H-1111 Budapest, Hungary \\ ${ }^{5}$ ENSAIT, GEMTEX, Univ. Lille North ofFrance, F-59100 Roubaix, France \\ *corresponding author: zineb.samouh@gmail.com
}

\begin{abstract}
:
The advantages of green composites are including, but not limited to their environmental friendly nature, lightweight, reduction of production energy and costs, recyclability. This work focuses on the mechanical, thermal and dynamic mechanical properties of biocomposites. For that purpose biosourced polymers were used, namely polylactic acid (PLA) and sisal fiber, and biocomposites were extruded and then injection molded with different contents of sisal fibers $(5 \%, 10 \%, 15 \%)$. The results show that the increase of the rate of reinforcement improves the mechanical and dynamic mechanical properties of the biocomposites made. By the increase of the sisal fiber content the degree of crystallinity of the matrix was increased from $47 \%$ to $61 \%$, as sisal fibers were acted as a nucleating agent for the PLA.
\end{abstract}

Keywords: biocomposites, sisal fiber, injection molding, mechanical properties, thermal properties.

\section{INTRODUCTION}

Environmental issues, such as the greenhouse effect, the $\mathrm{CO}_{2}$ emission and climate change have led researchers to develop alternative biomaterials to replace conventional ones. Among the developed materials, composites are significant, playing an important role in various fields (automotive, aeronautics, construction, etc.). Conventional composite materials are based on the usual non-biodegradable matrices and synthetic fibers. The researchers have found that natural fibers are alternatives of synthetic fibers, offering several advantages including: low cost, low density and biodegradability ${ }^{1-2}$.

Natural fiber composite reinforcements may be either plant origin such as alfa $^{3}$, ramie ${ }^{4}$, bamboo $^{5}$, or animal origin such as wool $^{6}$ or $\operatorname{silk}^{7}$. Several studies have been conducted on 
natural fiber reinforced polymer composites and non-degradable matrices. The review of Mittal et al. ${ }^{8}$ discusses the research activities that has been conducted recently in the field of natural fiber-reinforced epoxy composites. The results presented in this review shows that several factors of natural fiber (fiber content, fiber geometry including length and diameter, surface, compatibility, aggregation of fibers, etc.) that improve the mechanical, thermal and water absorption properties of the natural fibers reinforced epoxy composites.

Several comparative studies have been conducted on composites based on natural and synthetic fibers ${ }^{9-11}$. Composites based on natural fibers have the following advantages over composites based on synthetic fibers such as: low cost, biodegrability, low density, etc.

In recent years, the study of biodegradable polymers has been the subject of several studies ${ }^{12-}$ 13. The introduction of biodegradable polymers into composites offer a capacity for degradation and compatibility with the environment ${ }^{14-16}$. Several studies have been conducted to study the factor of the natural fiber content in the performance of biocomposites. The work of Torres-Telloa et al. ${ }^{17}$ showed that the increase of the content of agave fiber in biocomposites based on PHB (polyhydroxybutyrate) up to $30 \%$ can improve tensile, bending and impact properties. Czigány et al. ${ }^{18}$ has shown that increasing the basalt fiber content in PLA (polylactic acid) -based composites improves the tensile, flexural and impact properties. Bax et al. ${ }^{19}$ study found that the rate of flax fiber from $5 \%$ to $20 \%$ in PLA-based composites improves tensile and impact properties.

The effect of the natural fiber content on the thermal and dynamic mechanical properties of biocomposites was studied in several works. Gamon et $\mathrm{al}^{20}$ found that the increasing of the miscanthus fiber content from $10 \%$ to $40 \%$ in PLA do not modify the melting temperature of the polymer. The study of Anuar et al. ${ }^{21}$ showed that the increase of the kenaf fiber content in PLA improve the melting enthalpy of PLA. Cheng et al. ${ }^{22}$ studied the dynamic mechanical properties of chicken feather fiber reinforced PLA biocomposite in terms of storage \& loss modulus. It was found that the increase of the fiber content increase the storage modulus of the biopolymer.

Among the biopolymers, the polylactic acid polymer has an excellent balance of physical and rheological properties, many additives have been combined with it to further extend the range of properties achievable and thus optimize the biocomposites for specific end use applications. The most common fibers that have been combined with PLA are glass fibers and a limited selection of natural fibers including wood fibers and certain annually renewable plant fibers such as flax and kenaf.

The challenge presented in this work is to develop biocomposites based on the polylactic acid polymer based on natural Moroccan fibers with a low cost while improving the properties of the polymer by controlling the content of the natural fiber. 
Among the natural Moroccan fibers pine cone fiber ${ }^{23}$ and doum fiber ${ }^{24}$ are the ones which have been used in other works on biocomposites. Sisal fiber, which we used, is native in the northern regions of Morocco $^{25}$ and is currently applied mainly in traditional medicine ${ }^{26}$. Sisal plant is one of the most widely used natural fiber sources and is very easily cultivated. It is extracted from the leaves of the agave (agave sisalana) plant.

In our work, it was studied how the Moroccan sisal fiber modifies the properties of biocomposites of PLA matrix. This study was carried out to investigate the effect of the sisal fiber content on the mechanical and dynamic mechanical properties of biocomposites based on polylactic acid (PLA). The influence of Moroccan sisal fiber on the degree of crystallization of the PLA polymer was studied by DSC for the various fiber contents. The results reveal that Moroccan sisal fiber can possibly replace the synthetic nucleating agents of PLA.

\section{EXPERIMENTAL}

\subsection{Materials}

The Moroccan sisal fibers were extracted mechanically using a decorticator machine. After the extraction, the fibers were washed with water for 2 hours and then dried in an oven at 40 ${ }^{\circ} \mathrm{C}$ for 24 hours. After the fiber drying, the properties of sisal fibers were analyzed by various characterization methods. PLA (NatureWorks Ingeo 3100HP) with a melt flow index of 24 $\mathrm{g} / 10 \mathrm{~min}\left(\right.$ at $210^{\circ} \mathrm{C}$ and $2.16 \mathrm{~kg}$ ) was used as matrix of the composite.

\subsection{Preparation of the composites}

The PLA biodegradable polymer was mixed with various weight percents of sisal fiber (5\%, $10 \%, 15 \%$ ) and extruded by using a Labtech LTE 26-44 twin-screw extruder. The temperature profile in the various zones along the extruder was set to $190{ }^{\circ} \mathrm{C}$. The screw of the feeder was set at $20 \mathrm{rpm}$ and used for the PLA. The sisal fibers were added manually. As manual fiber feeding was applied, the $15 \%$ was the upper limit for the fiber content that the extruder could carry. The resulted strands were cut into $2 \mathrm{~mm}$ long granules using a strand pelletizer (LZ-120).

The composite specimens shown in Figure 1 were molded by using an Arburg Allrounder 270s injection molding machine. The injection speed was $50 \mathrm{~cm}^{3} / \mathrm{s}$ and the injection pressure was 1200 bar. The nominal cross section was 4 x $10 \mathrm{~mm}$, while the total length of the specimen was $170 \mathrm{~mm}$. The temperature of the mold was set at $25^{\circ} \mathrm{C}$ while the temperature of the injection unit's barrel was fixed at $190^{\circ} \mathrm{C}$. 


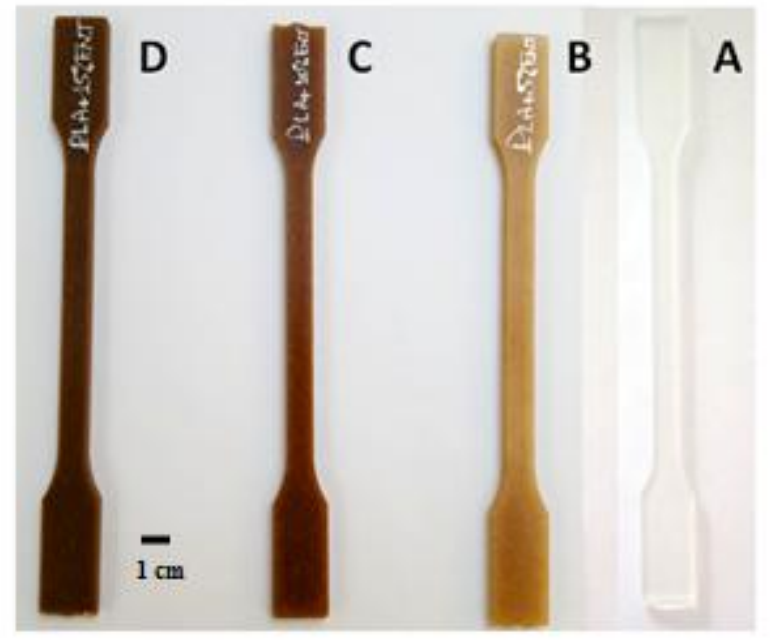

Figure 1: Standard type 1A tensile specimens of injection molded composites:

A) PLA ,B) PLA/5\% sisal fiber, C) PLA/10\% sisal fiber, D) PLA/15\% sisal fiber

\section{A, B, C, D must come from left to right. Scale bar $-10 \mathrm{~mm}$.}

Mirror the image and then put A, B, C, D

\subsection{Test methods of fibers}

\subsubsection{Morphological Analysis}

The surface characteristics of sisal fibers was studied by using a JEOL JSM 6380LA type scanning electron microscope.

\subsubsection{Thermogravimetric Analysis}

The thermal decomposition of sisal fiber was evaluated by thermogravimetric analysis (TGA) using a Q500 device of TA Instruments. Thermal analysis of sisal fibers was carried out according to ISO 11358. The sample (4 mg) was heated under nitrogen atmosphere from room temperature to $600{ }^{\circ} \mathrm{C}$ at a rate of $10^{\circ} \mathrm{C} / \mathrm{min}$ and the weight loss was monitored.

\subsubsection{FTIR Analysis}

The FTIR-analysis of sisal fibers was carried out using Thermo Scientific Smart OMNISampler spectrometer. The recorded wave number range was 4000 to $400 \mathrm{~cm}^{-1}$.

\subsubsection{Mechanical Testing}

The diameter of the sisal fiber was calculated on the basis of images taken by an Olympus BX51 optical microscope equipped with a digital camera. The tensile test of single sisal fibers was carried out by a universal load machine, namely a Zwick Z005, at a crosshead speed fixed at $5 \mathrm{~mm} / \mathrm{min}$, according to ISO 5079. Twenty samples of sisal fibers of $25 \mathrm{~mm}$ width was clamped between the grips of the tensile tester. Between the grips there was a distance of $5 \mathrm{~mm}$. 


\subsection{Characterization of Composites}

\subsubsection{Tensile Testing}

Tensile properties of composites were investigated according to ISO 527 by using a Zwick Z050 universal load machine. The tensile test was carried out at room temperature at a crosshead speed of $5 \mathrm{~mm} / \mathrm{min}$. Five samples of the injection molded composites were tested for each type of composite reinforced by different weight fractions of sisal fibers $(0 \%, 5 \%$, $10 \%, 15 \%)$. The specimens of the composites were evaluated and the average value was calculated.

\subsubsection{Flexural Testing}

Flexural test was carried out according to ISO 178. The flexural properties were measured by using three point bending test method on a Zwick Z050 universal load machine. The flexural test of specimens of the composites were evaluated at room temperature at a crosshead speed of $2 \mathrm{~mm} / \mathrm{min}$. Five samples of the injection molded composites were tested for each type of composite (5 wt $\%, 10 \mathrm{wt} \%, 15 \mathrm{wt} \%$ sisal fiber content) altogether with the five neat $(0 \%)$ reference specimens. The specimens of the composites were evaluated and the average value was calculated. Calculation of flexural strength $\left(\sigma_{\mathrm{fm}}\right)$ and flexural modulus $\left(\mathrm{E}_{\mathrm{f}}\right)$ by using formulae (1) and (2):

$$
\begin{gathered}
\sigma_{f M}=\frac{3 \mathrm{FL}}{2 \mathrm{bd}^{2}} \\
E_{f}=\frac{\mathrm{mL}^{\mathrm{s}}}{4 \mathrm{bd} \mathrm{d}^{\mathrm{s}}}
\end{gathered}
$$

$F$ is the ultimate failure load $(\mathrm{N}), L$ is the span between the center of supports $(\mathrm{mm}), m$ is the slope of tangent to the initial straight-line portion of the load-deflection curve, $b$ and $d$ are width and thickness, respectively.

\subsubsection{Charpy-impact testing}

Charpy-impact test was carried out by using a Ceast Resil Impactor Junior test machine. The specimens of composites were prepared as per ISO 179 with the dimensions of $60 \times 10 \times 4$ $\mathrm{mm}$. The impact speed was $2.9 \mathrm{~m} / \mathrm{s}$. Five samples of the injection molded composites were tested for each type of composite reinforced with sisal fibers of different weight fractions (5\%, 10\%, 15\%), as well as the neat PLA sample. The Charpy-impact strength of the composites specimens were evaluated and the average value was calculated.

\subsubsection{Dynamic mechanical analysis (DMA)}

The dynamic mechanical properties of the composites were performed by using a dynamic mechanical analyzer (model Q800 of TA Instruments, USA) operated in three-point bending 
mode. The specimens of the composites were prepared with the dimension of $60 \times 10 \times 4 \mathrm{~mm}$. The temperature range of the measurements was going from room temperature to $100{ }^{\circ} \mathrm{C}$ with a heating rate of $5{ }^{\circ} \mathrm{C} / \mathrm{min}$ and a constant frequency of $1 \mathrm{~Hz}$.

\subsubsection{Differential scanning calorimetry (DSC)}

The DSC analysis was conducted by using a Q2000 device from TA Instruments. The analyses were carried out in nitrogen atmosphere in a heat-cool-heat cycle in between -30 and $200^{\circ} \mathrm{C}$ with a heating and cooling rate of $5^{\circ} \mathrm{C} / \mathrm{min}$ and $10^{\circ} \mathrm{C} / \mathrm{min}$, respectively.

The degree of crystallinity $\left(\mathrm{X}_{\mathrm{C}}\right)$ of the samples was calculated according to (3):

$$
X c(\%)=\frac{\Delta H_{m}-\Delta H_{C C}}{\Delta H_{m r e f} *(1-x)} \cdot 100
$$

where $\Delta H_{m}$ is the melting enthalpy of the sample [J/g], while $\Delta H_{m r e f}$ is the melting enthalpy of the $100 \%$ crystalline PLA that is $93.7 \mathrm{~J} / \mathrm{g}$ according to the literature ${ }^{27} . \Delta \mathrm{H}_{\mathrm{cc}}[\mathrm{J} / \mathrm{g}]$ is the enthalpy of cold-crystallization and $x$ is the mass fraction of the sisal fibers.

\section{Results and discussion}

\subsection{Characterization of the sisal fibers}

\subsubsection{Morphological analysis}

The SEM image taken from the surface of sisal fiber is shown in Figure 2. The surface of the sisal fiber is rough that can be attributed to non-cellulosic components (waxy substances and impurities, such as hemicellulose or lignin $)^{28}$.
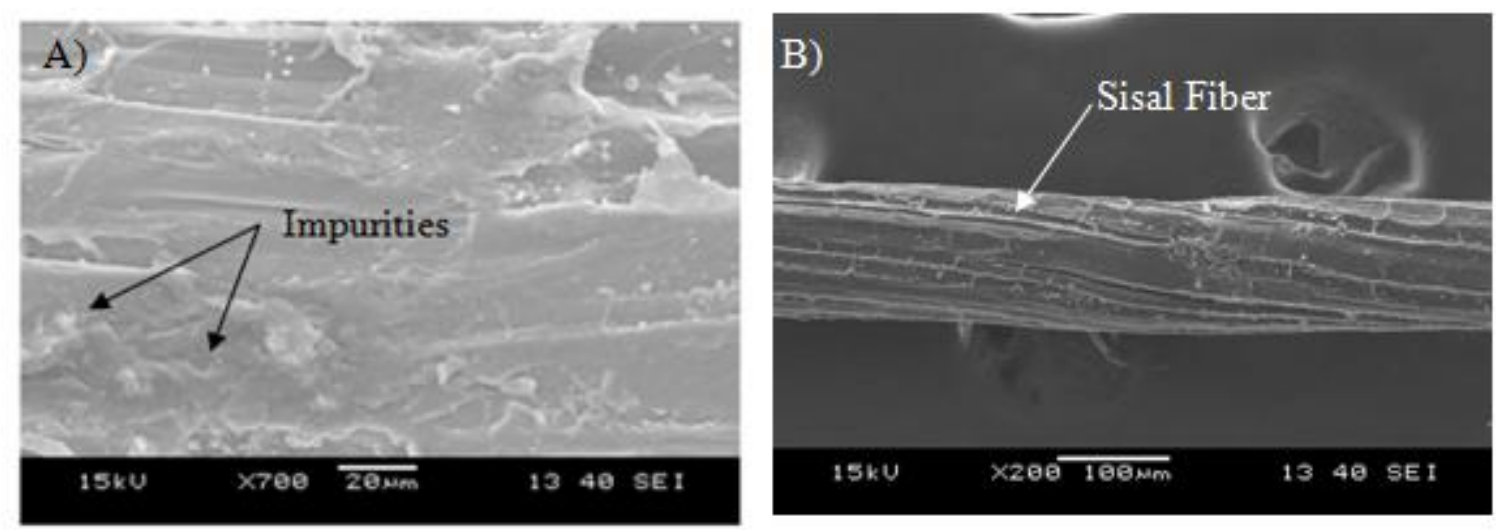

Figure 2: SEM micrographs of sisal fibers, a) extracted fibers, b) single fiber

\subsubsection{Thermogravimetric analysis}

The thermal stability of the sisal fiber is studied by thermogravimetric analysis (TGA). Thermal degradation (TD) and derived thermal degradation (DTD) curves (Figure 3.) present the steps of thermal degradation of sisal fiber. The first step of thermal decomposition of the sisal fiber can be observed below $150^{\circ} \mathrm{C}$, which is associated to the dehydration of sisal fiber. 
The weight loss at the first step of thermal degradation is $9.59 \%$. The second step of thermal decomposition of sisal fiber is attributed to the degradation of hemicelluloses of sisal fiber ${ }^{29}$, which occurred between $205{ }^{\circ} \mathrm{C}$ and $304{ }^{\circ} \mathrm{C}$, the weight loss at the second step of thermal degradation of sisal fiber is $20.4 \%$.The third step of thermal decomposition of sisal fiber can be observed between $270{ }^{\circ} \mathrm{C}$ and $390^{\circ} \mathrm{C}$, which is attributed to the degradation of cellulose $\mathrm{e}^{29}$. The last step of thermal decomposition of sisal fiber took place between $390{ }^{\circ} \mathrm{C}$ and $475{ }^{\circ} \mathrm{C}$, which is due to the presence of free radicals at oxidative atmosphere ${ }^{30}$. The thermal degradation of sisal fiber is similar to the thermal degradation of jute fiber studied by Khan et al. ${ }^{28}$. The total weight loss of sisal fiber was $98.22 \%$.
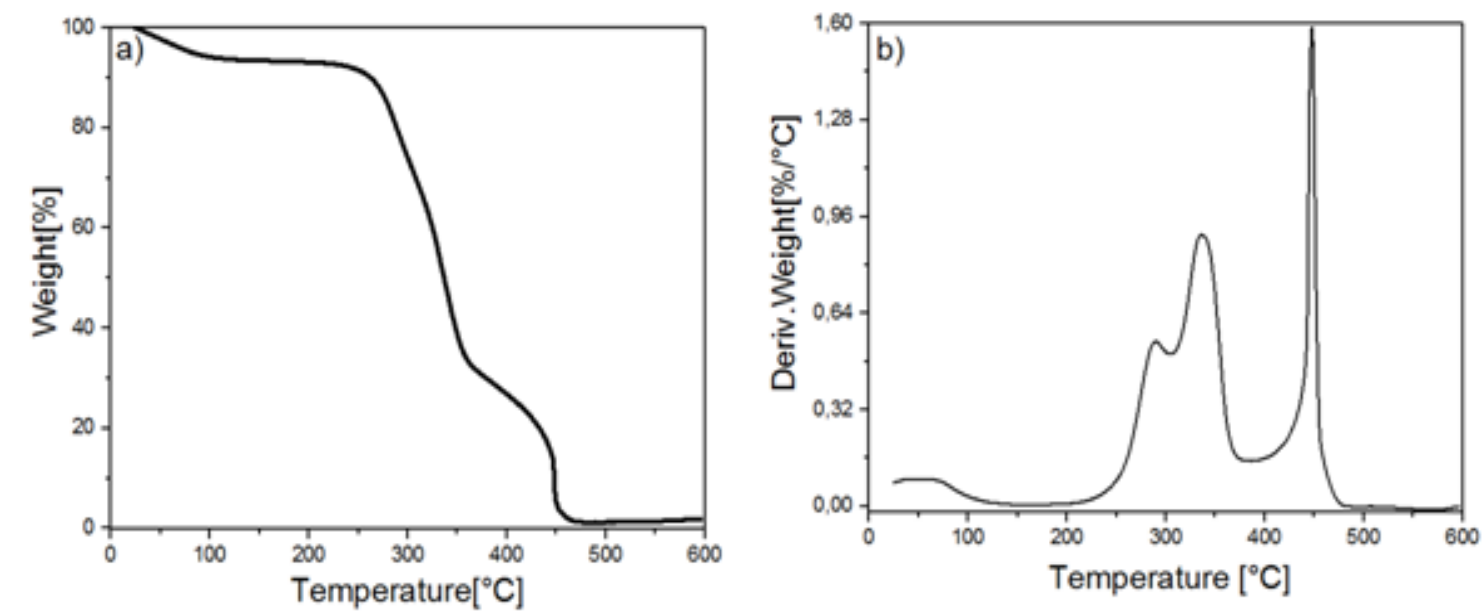

Figure 3: TD [a]and DTD [b] curve of sisal fiber

\subsubsection{FTIR analysis}

The infrared spectrum of sisal fiber shown in Figure 4. The chemical composition of sisal fiber studied by FTIR spectroscopy in this work is similar to that of natural fibers studied in previous papers ${ }^{30-31}$ and therefore the extraction by decortication was concluded to be successful. The band between $3200 \mathrm{~cm}^{-1}$ and $3400 \mathrm{~cm}^{-1}$ is attributed to the $\mathrm{O}-\mathrm{H}$ group indicating the presence of cellulose $\mathrm{e}^{12}$. The peak at $1742 \mathrm{~cm}^{-1}$ is associated with the elongation vibration of the carbonyl group $\mathrm{C}=\mathrm{O}$ indicating hemicelluloses in the fibers ${ }^{33}$. The peak between $1625 \mathrm{~cm}^{-1}$ and $1685 \mathrm{~cm}^{-1}$ is attributed to the vibration of $\mathrm{O}-\mathrm{H}$ group as water bound to lignin. ${ }^{34}$ The peak at $1540 \mathrm{~cm}^{-1}$ is attributed to the group corresponding to the vibration of the $\mathrm{C}-\mathrm{H}$ bond in the aromatic ring being present in the lignin. The peak at $1462 \mathrm{~cm}^{-1}$ corresponds to the deformation vibration of the lignin's $\mathrm{OCH}_{3}$ group ${ }^{34}$. The peaks at 1368 $\mathrm{cm}^{-1}$ and $1318 \mathrm{~cm}^{-1}$ are attributed to the vibration of deformation of the $\mathrm{CH}_{3}$ and $\mathrm{CH}_{2}$ groups of cellulose. The peak at $1050 \mathrm{~cm}^{-1}$ can be attributed to the deformation vibration of the C-O group showing the presence of cellulose in the sisal fiber ${ }^{32}$. 


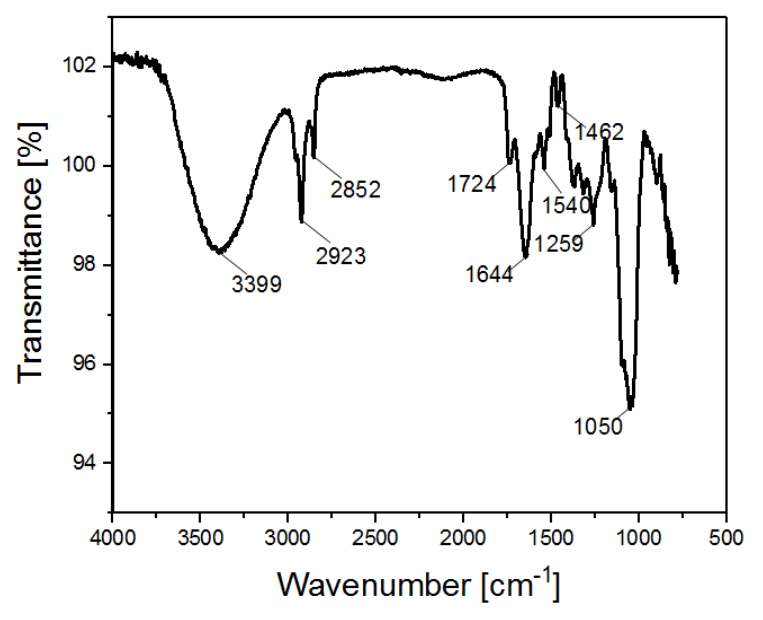

Figure 4: FTIR Spectrum of sisal fiber

\subsubsection{Mechanical testing:}

Figure 5 shows stress $v s$. strain curves of sisal fibers. There is no observable plasticity; the fiber exhibited an elastic, rigid break ${ }^{35}$. The measured mechanical properties of sisal fiber in this work are in agreement with works studying sisal fiber in the literature ${ }^{35-36}$ with minor differences originating from the different cultivation area and conditions.

Table 1 summarizes the mechanical properties of sisal fiber samples. The average diameter was $239.00 \pm 80.18 \mu \mathrm{m}$ as sisal is composed of rough, thick fibers. The calculated diameter is close to that of studied in the work of Belaadi et al. ${ }^{37}$ The average tensile strength of sisal fiber was $340.02 \pm 70.4 \mathrm{MPa}$ which also corresponds to the work of theirs (462 $\pm 71 \mathrm{MPa})$. The average Young's modulus of sisal fiber was $12.5 \pm 7.8 \mathrm{GPa}$, that is higher compared to the same literature $(7.47 \pm 1.37 \mathrm{GPa})$. The average elongation at break of sisal fiber is $3.2 \pm$ $0.8 \%$. Natural fibers can exhibit various mechanical properties originating from different cultivation experiences and naturally high difference of the specimens. The Moroccan sisal fiber of the current study had good properties enough to reinforce PLA matrices.

Table 1: Mechanical properties of the tested sisal fibers

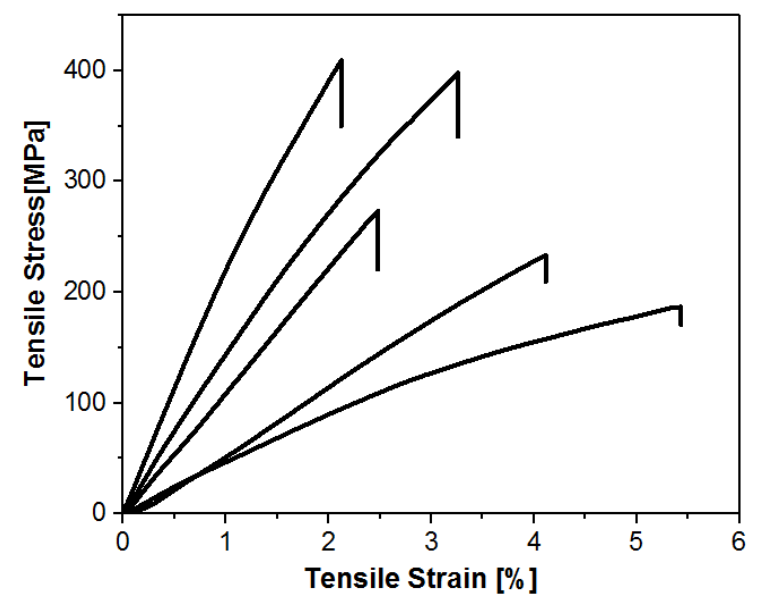

Figure 5: Tensile curves of five random samples of sisal fibers 


\subsection{Characterization of composites}

\subsubsection{Tensile testing}

The tensile properties of composites are shown in Figure 6 and Figure 7. It can be observed that the increase of sisal fiber content improves the tensile properties of the composites tested. The maximum value of tensile strength and modulus were found to be $70.76 \mathrm{MPa}$ and 4.6 $\mathrm{GPa}$, respectively, corresponding to the PLA/15\% sisal composite. Tensile strength of PLA/15\% sisal composite was $1.66 \%, 5.92 \%$ and $9.7 \%$ were higher than that PLA/5\% sisal, PLA/10\% sisal and neat PLA composites, respectively. Tensile Modulus of PLA/15\% sisal composite was $36.09 \%, 23.65 \%$ and $58.62 \%$ more than those of PLA/5\% sisal, PLA/10\% sisal, neat PLA composites, respectively.

In this work, the improvement of the tensile modulus was $58.56 \%$ for a sisal fiber content of $15 \%$ in PLA composites and the tensile strength a poor improvement of $9.7 \%$ for a sisal fiber content of $15 \%$. The improvement of tensile properties of PLA caused by the reinforcing sisal fibers were compared (Table 2).

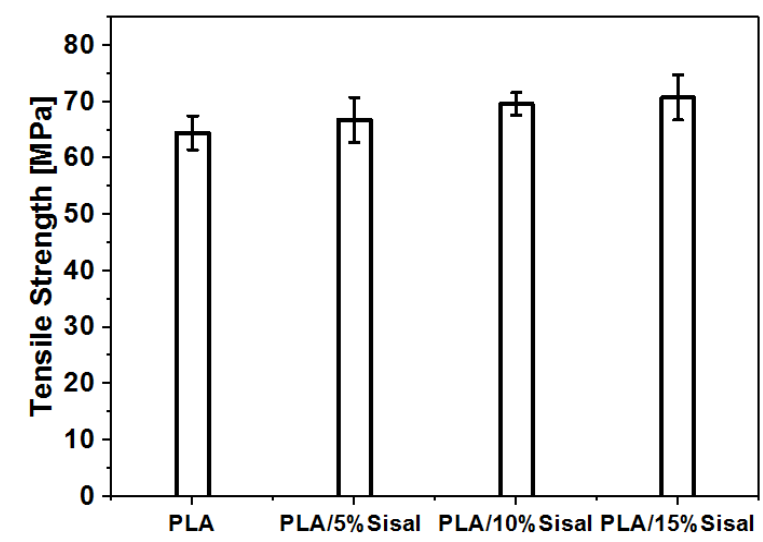

Figure 6: Tensile strength of the sisal /PLA composites

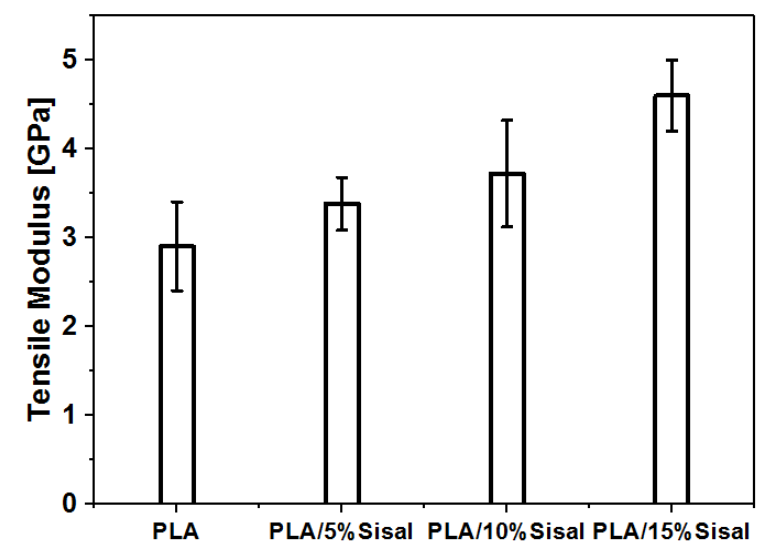

Figure 7: Tensile modulus of the sisal/PLA composites

\subsubsection{Flexural testing}


Flexural properties of the tested materials shown in Figure 8 and Figure 9. Both flexural strength and modulus are improved by the increase of fiber content in PLA composites. The PLA/15\% sisal composite had the maximum value of flexural strength and flexural modulus which were 135.1 MPa and 5.6 GPa, respectively. The improvement of the flexural properties of PLA in this study was compared with different works in Table 2. Flexural strength of PLA/15\% sisal composite was $23.26 \%$ higher, while flexural modulus of PLA $15 \%$ sisal composite was $80.64 \%$ higher than that of neat PLA. It has to be noted, that increasing the sisal fiber content improved the flexural modulus and tensile modulus of PLA composites.

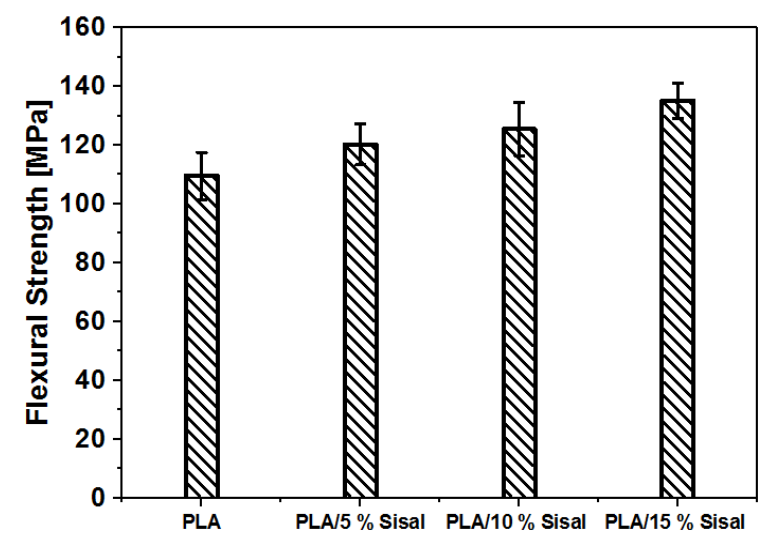

Figure 8: Flexural strength of sisal/PLA composites

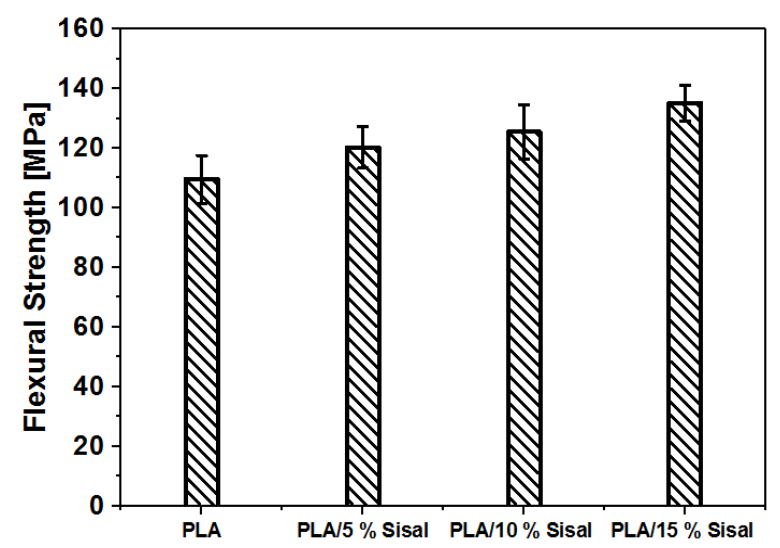

Figure 9: Flexural modulus of sisal/PLA composites

\subsubsection{Charpy-impact testing:}

The variation in the Charpy-impact strength of the composite with sisal fiber is given in Figure 10. It is clear from the diagrams that increasing the sisal fiber content from $0 \%$ to $15 \%$ in PLA composites improved the impact properties of composites that is quite an uncommon phenomenon in composites. Usually the matrix is the more ductile while the fibers exhibit high modulus and rigid behavior. This is not our case. The impact strength of neat PLA, 5\%, $10 \%$ and $15 \%$ sisal reinforced composites were found to be $2.97,3.28,3.56$ and $3.87 \mathrm{~kJ} / \mathrm{m}^{2}$, respectively. In this work the improvement of Charpy-impact strength was $30.30 \%$ for a sisal fiber content of $15 \%$ in PLA composites. This improvement was compared to different works in Table 2. The best improvement of Charpy-impact strength of PLA have been reached using 
flax fiber ${ }^{\mathrm{F}}$. PLA is a very rigid material under its glass transition temperature and even though sisal fibers have higher tensile strength, still they behaved more ductile then the matrix itself. Improving the strength and impact properties took place simultaneously that is a great advantage of the currently developed composite sisal/PLA materials.

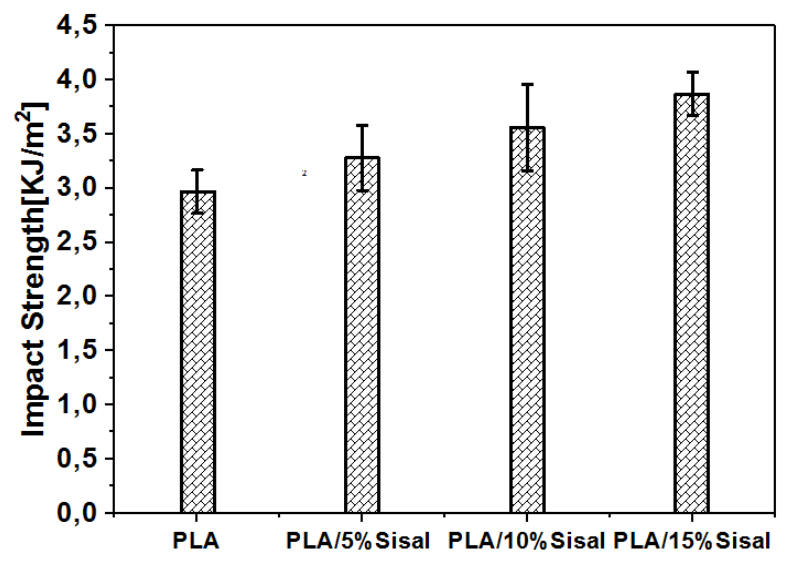

Figure 10: Charpy-impact strength of sisal/PLA composites

Table 2: Comparison of the mechanical properties of natural fibers reinforced PLA composites

\subsubsection{Differential scanning calorimetry (DSC)}

The thermal properties of the composites were investigated by DSC. The glass transition temperature $\left(\mathrm{T}_{\mathrm{g}}\right)$ of neat PLA was $58{ }^{\circ} \mathrm{C}$ (Table 2). It can be seen that the reinforcement of PLA with different sisal fiber content $(5 \%, 10 \%, 15 \%)$ did not modify this value, the presence of sisal fibers did not influence the mobility of the molecular chains of PLA. That can be attributed to the large diameter of sisal fibers (small specific area to connect to the matrix).

The melting temperature of the first and second heating cycles of the composites are shown in Table 2. It can be observed that the melting temperature of the first heating cycle was around $175^{\circ} \mathrm{C}$ and the melting temperature of the second heating cycle was around $176^{\circ} \mathrm{C}$. Adding the sisal fiber in PLA did not modify the melting temperature of PLA. Again, it can be attributed to the relatively large size of sisal fibers and the relatively small boundary layer in between the fiber and the matrix.

Figure 11 shows the enthalpy of crystal melting in the second heating cycle for the composites. The reinforcement of sisal fiber in PLA composites increased the melting enthalpy of composites compared to the neat PLA. The enthalpy melting of 5-10-15\% sisal containing composites was $14 \%, 17 \%$ and $7.5 \%$ higher than that of neat PLA respectively.

The results in Table 2 clearly indicate that the adding of sisal fiber in PLA composites improve the crystallization of PLA composites. The $10 \%$ sisal fiber content in PLA composite renders a high degree of crystallinity compared to that of the $5 \%$ and $15 \%$ sisal fiber content in PLA composite. In general, PLA crystallization can be increased by adding a 
nucleation agent ${ }^{27}$. The results show that the $10 \%$ fiber content of sisal fiber in PLA composites were more crystallites were formed in the PLA/ $10 \%$ by weight of fiber composites due to the role of natural fibers as a nucleating agent. Beyond the $10 \%$ sisal fiber content, the fibers have possibly become barriers that prevent growth of spherulites of PLA. Moreover, because the $15 \%$ was an upper limit of fiber content due to manual feeding, fibers were possibly aggregated and/or did not dispersed homogeneously in the matrix resulting in a different microstructure.

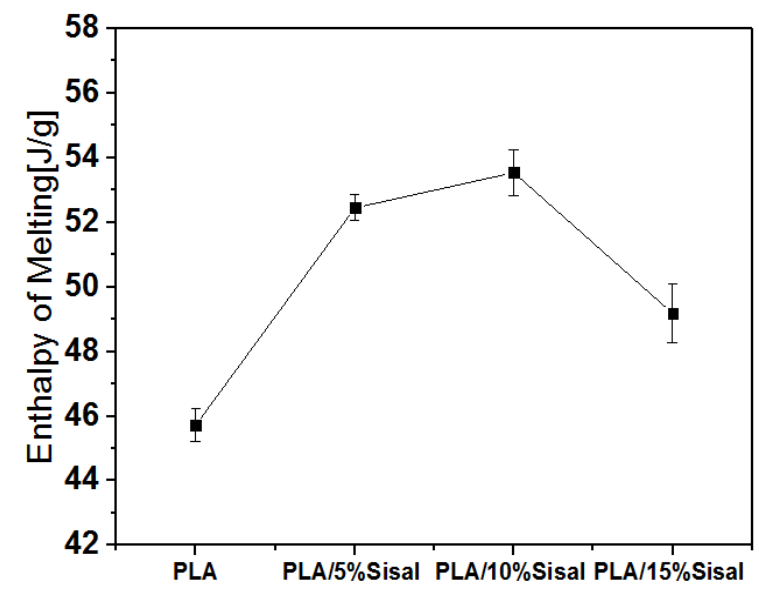

Figure 11: Enthalpy of melting of sisal/PLA composites

\subsubsection{Dynamic Mechanical Analysis (DMA)}

Figure 12 shows the storage modulus of sisal fiber reinforced PLA composites. The storage modulus of neat PLA, PLA/5\% sisal, PLA/10\% sisal and PLA/15\% sisal composites were 2623, 3430, 3015 and $2723 \mathrm{MPa}$, respectively. It must be noted, that the increase of the sisal fiber content in PLA composites improved the storage modulus of PLA composites in the glassy state that also suggest the nucleating effect of the fibers.

The decrease in the storage modulus above $50{ }^{\circ} \mathrm{C}$ is due to the transition of the amorphous parts of the matrix from the glassy to the rubbery state. When reaching the rubbery state with the amorphous part of the matrix, the storage modulus of neat PLA, PLA/5\% sisal, PLA/10\% sisal and PLA/15\% sisal composites were 207.81, 218.3, 224.9 and 245.0 MPa, respectively. The improvement of the storage modulus of sisal fiber reinforced PLA composites by the increasing of sisal fiber content in this study was similar to the result by Shakoor et al. ${ }^{38}$ who studied the effect of increasing hemp fiber content in PLA composites. 


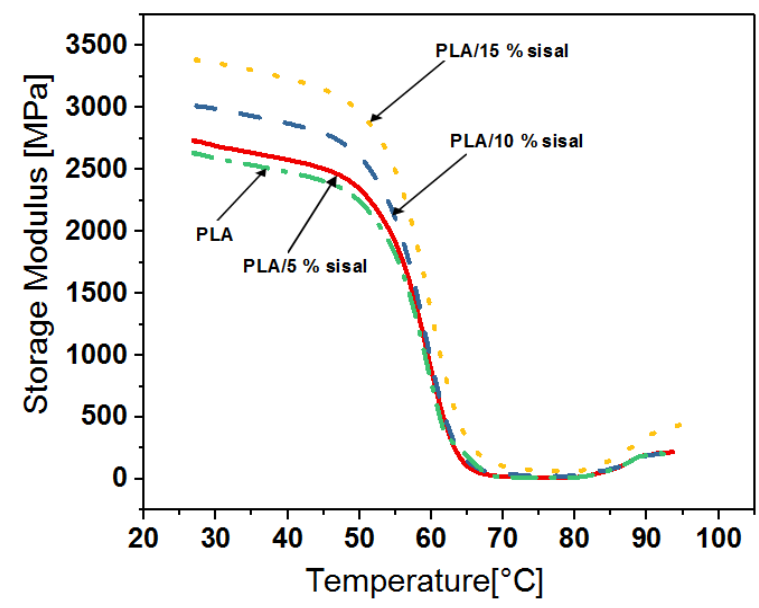

Figure 12: Storage modulus curves of PLA/sisal fiber composites

Figure 13 shows the loss modulus of sisal fibers reinforced PLA composites. The loss modulus curve allows the temperature of the glass transition to be determined. The values of the glass transition temperature of PLA composites are around $60{ }^{\circ} \mathrm{C}$ from the location of the first peak. This result fits to our DSC values, which shows that sisal fibers do not modify the mobility of PLA matrix molecules due to their bulky nature making the material greatly inhomogeneous. In the study of Shakoor et al. ${ }^{38}$ the glass transition temperature of the composites remains unchanged by the addition of hemp fibers in PLA composites.

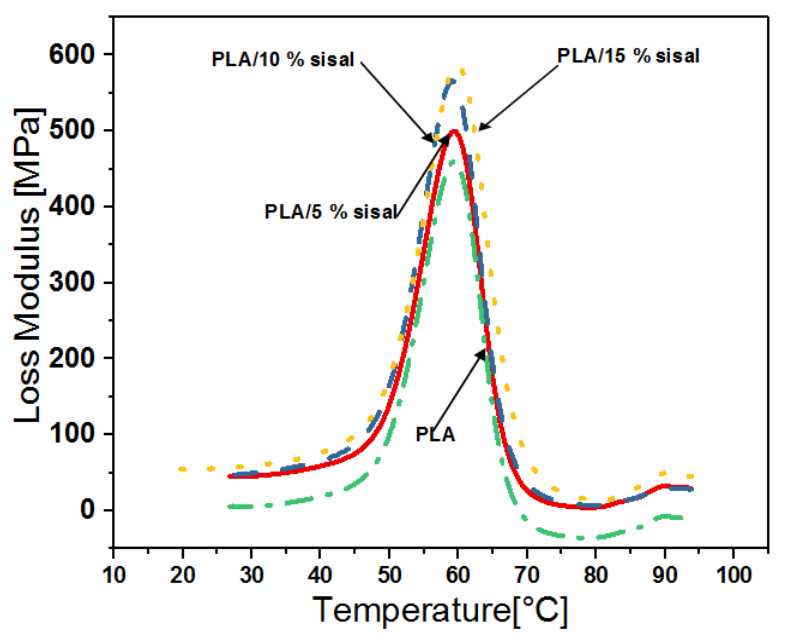

Figure 13 : Loss modulus curves of PLA/sisal fiber composites

Figure 14 shows the loss factor $(\tan \delta)$ of the PLA/sisal fiber composites. The higher value of $\tan \delta$ corresponds to neat PLA. The increase of the sisal fiber content in PLA composites decreased the loss factor. This decrease is due to the meager damping capability of the composites around the glass transition of PLA. Higher fiber content had higher degree of crystallinity in general (i.e. less amorphous), thus gradually less molecule segments became mobile, which corresponds to lower loss factors. The nucleating effect of sisal fibers revealed again. The glass transition temperature of PLA composite reinforced with different contents of sisal fiber $(5 \%, 10 \%, 15 \%)$ from the loss factor curves was $66^{\circ} \mathrm{C}$. 


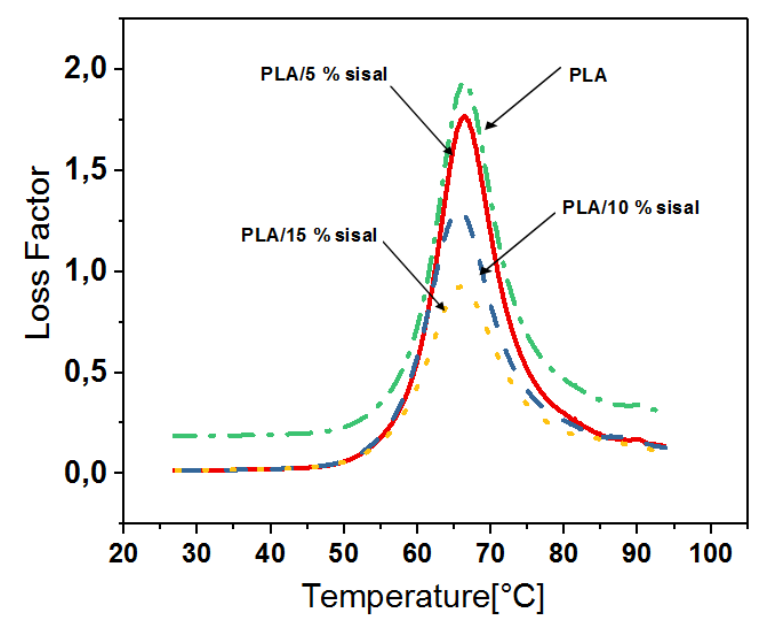

Figure 14: Loss factor curves of PLA/sisal fiber composites

\section{Conclusion}

This work investigated the influence of sisal fiber content on the properties of sisal fiber reinforced PLA composites. Compounding was carried out by twin-screw extrusion and the material was then injection molded into composite samples.

The tensile properties of PLA composites reinforced with different contents of sisal fiber (5\%, $10 \%, 15 \%$ ) shown that the increase of the sisal fiber content in PLA composites gradually improved the tensile strength, tensile modulus flexural and impact properties. It is interesting that PLA is rigid and therefore increasing the fiber content improved the Charpy-impact properties, hence the material has higher strength and impact resistance at the same time.

The dynamic mechanical (DMA) tests and the DSC studies both demonstrated that increasing of sisal fiber in PLA composites did not alter the glass transition temperature of the PLA matrix. The loss factor of composites decrease by the increasing of the content of sisal fiber in PLA composites. The sisal fiber act as a nucleating agent of the PLA, hence it increases the degree of crystallinity in the PLA martrix and also decreases the loss factor around $\mathrm{T}_{\mathrm{g}}$, related to the smaller amount of the amorphous phase. Our results reveal that sisal fiber can possibly replace the synthetic nucleating agents of PLA maintaining the completely biodegradable characteristic of the composite material.

\section{References:}

1. Bogoeva G G, Avella M, Malinconico M, Buzarovska A,

Grozdanov A, Gentile G, Errico M E. Natural fiber eco-composites. Polym Compos. 2007;28:98-107 .

2.

Mohanty A K, Misra M, Drzal L T. Sustainable bio-

composites from renewable resources: opportunities and challenges in the green materials world. J Polym Environ. 2002;10:19-26. 
3. Belhassen R, Boufi S, Vilaseca F, Lopez J P, Méndez J A, Franco E, Pélach M A, Mutje P. Biocomposites based on Alfa fibers and starch based biopolymer. Polym Adv Technol. 2009;20:1068-1075.

4. Chen D, Li J, Ren J. Biocomposites based on ramie fibers and poly (L-lactic acid)(PLLA): morphology and properties. Polym Adv Technol. 2012;23:198-207.

5.Zakikhani P, Zahari R, Sultan M T H, Majid D L. Extraction and preparation of bamboo fibre-reinforced composites. Mater Des. 2014;63:820-828.

6. Fantilli A P, Sicardi S, Dotti F. The use of wool as fiber-reinforcement in cement-based mortar. Constr Build Mater. 2017;139:562-569.

7. Akash S, Avinash S, Ramachandra M. A Study on mechanical properties of silk fiber reinforced epoxy resin bio-composite with $\mathrm{SiC}$ as filler addition. Mater Today-Proc. 2018;5:3219-3228.

8. Mittal V, Saini R, Sinha S. Natural fiber-mediated epoxy composites-A review. Compos Part B. 2016;99:425-435.

9. Joshia S V, Drzalb L T, Mohantyb A K, Arorac S. Are natural fiber composites environmentally superior to glass fiber reinforced composites? Compos Part A. 2004;35:371376.

10. Wu Y, Xia C, Cai L, Garcia A C, Shi S Q. Development of natural fiber-reinforced composite with comparable mechanical properties and reduced energy consumption and environmental impacts for replacing automotive glass-fiber sheet molding compound. J Cleaner Prod. 2018;184:92-100.

11. Biswas S, Satapathy A. comparative study on erosion characteristics of red mud filled bamboo-epoxy and glass-epoxy composites. Mater Des. 2010;31:1752-1767.

12. Leja K, Lewandowicz G. Polymer biodegradation and biodegradable polymers-a review. Polish J Environ Stud. 2010;19:255-266.

13. Kolybaba M, Tabil L G, Panigrahi S, Crerar W J, Powell T, Wang B. biodegradable polymers: past, present, and future. In: ASABE/CSBE North Central Intersectional Meeting. American Society of Agricultural and Biological Engineers, USA. 2006. pp.1-15.

14. Saiful I A, Noor F A S, Wan A W A R. Biodegradable polymers and their bone applications: A Review. Int J Basic Appl Sci. 2012;12:31-49.

15. Sahari J, Sapuan S M. Natural fibre reinforced biodegradable polymer composites. Rev Adv Mater.Sci. 2011;30:166-174.

16. Sharath S H S, Ramachandra M. Green composites: a review. Mater Today Proc. 2018;5(1):2518-2526.

17. Torres-Tello E V, Robledo-Ortíz J R, González-García Y, Pérez-Fonseca A A, JassoGastinel C F, Mendizábal E. Effect of agave fiber content in the thermal and mechanical 
properties of green composites based on polyhydroxybutyrate orpoly(hydroxybutyrate-cohydroxyvalerate). Ind Crops Prod. 2017;99:117-125.

18. Czigány T, Kovács J G, Tábi T. Basalt fiber reinforced poly(lactic acid) composites for engineering applications. In: International conference on composite materials (ICCM19) 2013:4377-4384.

19. Bax B, Müssig J. Impact and tensile properties of PLA/Cordenka and PLA/flax composites. Compos Sci Technol. 2009;68:1601-1607.

20. Gamon G, Evon P, Rigal L. Twin-screw extrusion impact on natural fibre morphology and material properties in poly (lactic acid) based biocomposites. Ind Crops Prod. 2013;46:173-185.

21. Anuar H, Ahmad Z. Thermal properties of injection moulded polylactic acid-kenaf fibre biocomposite. Malaysian Polym J. 2011;6:51-57.

22. Shinoj S, Visvanathan R, Panigrahi S, Varadharaju N. Dynamic mechanical properties of oil palm fibre (OPF)-linear low density polyethylene (LLDPE) biocomposites and study of fibre-matrix interactions. Biosyst Eng. 2011;109:99-107.

23. Arrakhiz F Z, El Achaby M, Benmoussa K, Bouhfid R, Essassi E M, Qaiss A, Evaluation of mechanical and thermal properties of Pine cone fibers reinforced compatibilized polypropylene. Mater Des. 2012;40:528-535.

24. Arrakhiz F Z, El Achaby M, Malha M, Bensalah M O, Fassi-Fehri O, Bouhfid R, Benmoussa K, Qaiss A. Mechanical and thermal properties of natural fibers reinforced polymer composites:Doum/low density polyethylene. Mater Des. 2013;43:200-205.

25. El-Hilaly J, Hmammouchi M, Lyoussi B. Ethnobotanical studies and economic evaluation of medicinal plants in Taounate province (Northern Morocco). J Ethnopharmacol. 2003;86:149-158.

26. Fennane M, Rejdali M. Aromatic and medicinal plants of Morocco: Richness, diversity and threats. Bulletin de l'Institut Scientifique, Rabat, Section Sciences de la Vie. 2016;38.

27. Fehri S, Cinelli P, Coltelli M-B, Anguillesi I, Lazzeri A. Thermal properties of plasticized poly(lactic acid) (PLA) containing nucleating agent. Int. J Chem Eng Appl. 2016;7:85-88.

28. Khan J A, Khan M A, Islam R, Gafur A. Mechanical, thermal and interfacial properties of jute fabric-reinforced polypropylene composites: Effect of potassium dichromatem. Mater Sci Appl. 2010;1:350-357.

29. Martina A R, Martins M A, Silva O R D, Mattoso L H C. Studies on the thermal properties of sisal fiber and its constituents. Thermochim Acta. 2010;506:14-19.

30. Barreto A C H, Rosa D S, Fechine P B A, Mazzetto S E. Properties of sisal fibers treated by alkali solution and their application into cardanol-based biocomposites. Composites: Part A. 2011;42:492-500. 
31. Fan M, Dai D, Huang B. Fourier Spectroscopy for natural fibres transform infrared. In: Salih S. Fourier transform materials analysis. InTech, London; 2012:45-68.

32. Hinterstoisser B, Salmén L. Application of dynamic 2D FTIR to cellulose. Vib Spectrosc. 2000;22:111-118.

33. Srivastava H C, Adams G A. Uronic acid components of jute fiber hemicellulose. J Am Chem Soc. 1959;81:2409-2412.

34. Hergert H L, Kurth E F. The infrared spectra of lignin and related compounds. I.: characteristic carbonyl and hydroxyl frequencies of some flavanones, flavones, chalcones and acetophenones. J Am Chem Soc. 1953;75:1622-1625.

35. Silva F D A, Chawla N, Filho R D D T. Tensile behavior of high performance natural (sisal) fibers. Compos Sci Technol. 2008;68:3438-3443.

36. Rao K M M, Rao K M. Extraction and tensile properties of natural fibers: Vakka, date and bamboo. Compos Struct. 2007;77:288-295.

37. Belaadi A, Bezazi A, Bourchak M, Scarpa F. Tensile static and fatigue behaviour of sisal fibres. Mater Des. 2013;46:76-83.

38. Shakoor A, Muhammad R, Thomas N L, Silberschmidt V V. Mechanical and thermal characterisation of poly(l-lactide) composites reinforced with hemp fibres. J Phys: Conf Ser. 2013;45(1).

39. Sawpan M A, Pickering K L, Fernyhough A. Hemp fibre reinforced poly (lactic acid) composites. Adv Mater Res. 2007;29:337-340.

40. Finkenstadt V L, Liu L S, Willett J L. Evaluation of poly (lactic acid) and sugar beet pulp green composites. J Polym Environ 2007;15:1-6.

41. Bledzki A K, Jaszkiewicz A Scherzer D. Mechanical properties of PLA composites with man-made cellulose and abaca fibres. Compos Part A. 2009;40:404-412. 
Tables:

Table .1: Mechanical properties of the tested sisal fibers

Diameter interval $[\mu \mathrm{m}]$

Average diameter $[\mu \mathrm{m}]$

Elongation at break interval [\%]

Elongation at break [\%]

Tensile strength interval [MPa]

Tensile strength [MPa]

Young's modulus interval [GPa]

Young's Modulus [GPa]

$$
\begin{gathered}
121.6-411.0 \\
239.0 \pm 80.18 \\
2.47-5.50 \\
3.2 \pm 0.8 \\
186,9.7-409.4 \\
340.02 \pm 70.4 \\
4.89-23.29 \\
12.5 \pm 7.8
\end{gathered}
$$


Table 2: Comparison of the mechanical properties of natural fibers reinforced PLA composites

\begin{tabular}{|c|c|c|c|c|c|c|c|}
\hline & $\begin{array}{c}\text { Fiber } \\
\text { content } \\
{[\%]}\end{array}$ & $\begin{array}{c}\text { Tensile } \\
\text { strength } \\
\text { [MPa] }\end{array}$ & $\begin{array}{c}\text { Tensile } \\
\text { modulus } \\
{[\mathrm{MPa}]}\end{array}$ & $\begin{array}{c}\text { Flexural } \\
\text { strength } \\
{[\mathrm{MPa}]}\end{array}$ & $\begin{array}{c}\text { Flexural } \\
\text { modulus } \\
{[\mathrm{MPa}]}\end{array}$ & $\begin{array}{l}\text { Charpy impact } \\
\text { strength }\left[\mathrm{kJ} / \mathrm{m}^{2}\right]\end{array}$ & $\begin{array}{c}\text { Reference } \\
\text { No. }\end{array}$ \\
\hline PLA/hemp & 30 & $2.2 \%$ & $70 \%$ & - & - & - & 39 \\
\hline $\begin{array}{c}\text { PLA/man } \\
\text { made } \\
\text { cellulose }\end{array}$ & 30 & - & - & $39.44 \%$ & $154 \%$ & - & 41 \\
\hline PLA/ flax & 30 & - & - & - & - & $40 \%$ & 41 \\
\hline PLA/basalt & 15 & $42.01 \%$ & $77.58 \%$ & $24.72 \%$ & $89 \%$ & $98.4 \%$ & 18 \\
\hline PLA/abaca & 30 & $14.72 \%$ & $80 \%$ & $13.13 \%$ & $101 \%$ & - & 40 \\
\hline PLA/sisal & 15 & $9.7 \%$ & $58.62 \%$ & $23.26 \%$ & $80.64 \%$ & $30.30 \%$ & Current study \\
\hline
\end{tabular}


Table. 3: Thermal properties of sisal/PLA composites

\begin{tabular}{|c|c|c|c|c|}
\hline & PLA & $\begin{array}{c}\text { PLA/5\% } \\
\text { sisal }\end{array}$ & $\begin{array}{c}\text { PLA/10\% } \\
\text { sisal }\end{array}$ & $\begin{array}{c}\text { PLA/15\% } \\
\text { sisal }\end{array}$ \\
\hline $\begin{array}{l}\text { Glass transition temperature }\left(\mathbf{T}_{\mathrm{g}}\right) \\
\qquad\left[{ }^{\circ} \mathrm{C}\right]\end{array}$ & 58.3 & 58.5 & 58.5 & 58.1 \\
\hline Melting temperature $1^{\text {st }}$ cycle $\left[{ }^{\circ} \mathrm{C}\right]$ & 175.8 & 174.2 & 174.7 & 174.1 \\
\hline Melting temperature $2^{\text {nd }}$ cycle $\left[{ }^{\circ} \mathrm{C}\right]$ & 176.3 & 175.6 & 175.8 & 175.1 \\
\hline Degree of crystallinity [\%] & 46.98 & 58.4 & 61.2 & 57.3 \\
\hline
\end{tabular}

